\title{
Application of poly (Agar-co-Glycerol-co-Sweet Almond Oil) based organohydrogels as a Drug Delivery Material
}

Tuba Ersen Dudu ( $\nabla$ tuba_ersen@hotmail.com )

Van Yuzuncu Yil University: Van Yuzuncu Yil Universitesi https://orcid.org/0000-0001-5564-2834

Duygu Alpaslan

Van Yuzuncu Yil University: Van Yuzuncu Yil Universitesi

Nahit Aktas

Manas University: Kyrgyz-Turkish Manas University

\section{Research Article}

Keywords: Organohydrogel, Agar, Swelling, Sweet Almond Oil, Ceftriaxone, Oxaliplatin

Posted Date: March 30th, 2021

DOl: https://doi.org/10.21203/rs.3.rs-355013/v1

License: (c) (1) This work is licensed under a Creative Commons Attribution 4.0 International License.

Read Full License 


\section{Abstract}

In this study, it was aimed to investigate the synthesis, characterization and drug release behaviors of organohydrogels containing pH-sensitive Agar (A), Glycerol (G), Sweet Almond oil (SAO). Organohydrogels, which contained Agar, Glycerol and different amounts of Sweet Almond oil, were synthesized via the free-radical polymerization reaction with emulsion technique using glutaraldehyde or methylene bis acrylamide crosslinkers. Then, the degree of swelling, bond structures, blood compatibility and antioxidant properties of the synthesized organohydrogels were examined. In addition, Organohydrogels which loaded with Ceftriaxone (antibiotic) and Oxaliplatin (an anti-cancer agent), were synthesized with the same polymerization reaction and release kinetics were investigated. In vitro release studies were performed at media similar $\mathrm{pH}$ to gastric fluid $(\mathrm{pH} 2)$, skin surface $(\mathrm{pH} 5.5)$, blood fluid $(\mathrm{pH}$ 7.4) and intestinal fluid ( $\mathrm{pH} 8)$, at $37^{\circ} \mathrm{C}$. The effects on release of crosslinker type and sweet almond oil amount were investigated. Kinetic parameters were determined using release results and these results were applied to zero and first-order equations and Korsmeyer-Peppas and Higuchi equations. Diffusion exponential was calculated for drug diffusion of organohydrogels and values consistent with release results were found.

\section{Introduction}

Recently, it has been hypothesized that fatty acid-based hydrophobic organogels will form a matrix suitable for long-term release of hydrophilic molecules. Organogels have advantages as a drug delivery system. Since drug carrier organohydrogels are not affected by moisture; Since they provide the drug to pass easily through the skin; as they are resistant to microbial contamination; they have many advantages. As a drug carrier of organohydrogels, the gelling and trapping procedures were quite simple and useful. Biocompatibility, biodegradability and non-immunogenic properties of the organogel show that it is non-hazardous in their long-term use. However, the use of organogels as drug carriers is becoming widespread [1-6].

In sweet almond oil, the main components are contained $5.26-7 \%$ palmitic acid, $0.33-0.6 \%$ palmitoleic acid, $1.61-4.40 \%$ stearic acid, $65.33-76.73 \%$ oleic acid, $17.36-25.17 \%$ linoleic acid, $0.44-0.64 \%$ myristic acid, $21.25-17.89 \%$ linoleic acid, $90.50-92.1 \%$ unsaturated fatty acids, 7.61-11.48\% saturated fatty acids ratio. There is a great deal of scientific research that sweet almond oil has anti-inflammatory, immuneenhancing and anti-hepatotoxicity effects and prevents the growth of primary and metastatic colon cancer cells [7-10].

Ceftriaxone is a cephalosporin gruop antibiotic, which is often preferred in the treatment of bacterial infections. Ceftriaxone is frequently used in children due to its advantages such as long half-life, wide range of activity, high penetration into tissues and high reliability. Currently, although no effective therapy or vaccine has been produced for COVID-19, it has been reported in the literature that ceftriaxone antibiotics are used for treatment in patients with the COVID-19 virus $[11,12]$. 
Oxaliplatin is a third-generation platinum analog used in the treatment of colorectal cancer (CRC). The platinum compound used in colorectal cancer treatment causes oxaliplatin, acute motor and sensory symptoms, and chronic neuropathy with cumulative dose. The anti-tumor effect of oxaliplatin is thought to be due to the formation of linkages that disrupt DNA synthesis [13-15].

Within the scope of the study presented, preparation of organohydrogels based on different cross-linker type (glutaraldehyde $(\mathrm{G})$ and Agar Glycerol and Sweet almond oil loaded with different types of ceftriaxone and carboplatin ( $\mathrm{p}$ (AG-CO-SAO)), swelling and FT-IR analysis and its characterization, antioxidant and blood compatibility properties, and these organohydrogels drug-release studies have been investigated in vitro conditions Organohydrogels systems have been prepared using the free radical polymerization technique in the emulsion media method. The drug-loaded organohydrogels release kinetics at different $\mathrm{pH}$ were interpreted to investigate the release behaviors. Organohydrogels release behaviors were compared to investigate the effect of ceftriaxone and carboplatin drugs on release kinetics.

\section{Materials And Methods}

\section{Agar-Glycerol-based gels and hydrogels synthesis}

Agar-Glycerol based gel and hydrogels were synthesized via free radical polymerization in emulsion according to the preparation method given in Table 1. Gel and hydrogels were synthesized as described by Alpaslan et al[16]. Gel and hydrogel compositions were given in Table 2. For the preparation of organohydrogels above given method was used (Table 1$)$. Shortly; agar solution ( $2 \mathrm{~mL})$, glycerol $(0.04$ $\mathrm{mL})$, and Sweet Almond oil $(0.1,0.2$ and $0.3 \mathrm{~mL}$ ) were added to the $21 \mathrm{~mL}$ vial and made homogeneous by vortex (at $2500 \mathrm{rpm}$ for $15 \mathrm{~min}$ ) until the formation of a clear homogeneous solution emulsion. Crosslinker reagent was added and further homogenized. Organohydrogel compositions were showed in Table 2. The polymerization reaction was initiated by the addition of the initiator solution APS in $0.1 \mathrm{~mL}$ DI water. Reaction were maintained at $25^{\circ} \mathrm{C}$ with a temperature-controlled hot plate. These preparation steps are schematically given in Figure 1 . The gel, hydrogels and organohydrogels were kept in DI water. Finally, the synthesized materials were dried until a constant weight was achieved and stored at $4^{\circ} \mathrm{C}$ for further uses.

\section{Organohydrogel synthesis containing Ceftriaxone and Oxaliplatin}

Ceftriaxone or Oxaliplatin drugs were directly synthesized with organohydrogel [17]. The synthesis of Ceftriaxone/Oxaliplatin-loaded organohydrogels was the same as the synthesis procedure of the organohydrogels described above. In addition to only the reaction mixture mentioned above, Ceftriaxone or Oxaliplatin (50 ppm $1 \mathrm{~mL}$ ) were added.

\section{Characterization of organohydrogels}


Swelling analysis were performed with certain amounts of dried materials placed in ethanol, water, acetone, ethanol/IDwater (1:1), gasoline and acetone/IDwater (1:1) different 2-12 pHs for a day. Swelling tests were performed at $25^{\circ} \mathrm{C}[18,19]$.

The FT-IR spectra of organohydrogel was obtained from a Thermo Scientific Nicolet iS10 instrument using ATR apparats with $4 \mathrm{~cm}^{-1}$ resolution between $4000-650 \mathrm{~cm}^{-1}$

To evaluate the blood clotting [16] and hemolysis analysis [20] methods which were explained in the literature were applied.

To evaluate the antioxidant activity, FC [21-23] and ABTS $[22,24]$ methods which were emphases in the literature were applied.

\section{Ceftriaxone and Oxaliplatin release studies}

Synthesized drug-loaded gel, hydrogels and organohydrogels were used as controlled release systems for Ceftriaxone (antibiotic) and Oxaliplatin (an anti-cancer agent), which are frequently used in the medical field The release methods [16] [20] which were explained in the literature were applied. Released Ceftriaxone and Oxaliplatin quantities were calculated on the calibration curves prepared at $244 \mathrm{~nm}$ and $210 \mathrm{~nm}$ amount were calculated on the calibration curves measurement in the UVVis-spectrophotometer, respectively. The most prevalent models was used. Those equations were showed in Table 3.

\section{Results And Discussion}

\section{Swelling properties of the Organohydrogels}

Swelling work carried out in polar and apolar environments is a widely used technique for characterizing gel, hydrogel and organohydrogels. Both kinetic and dynamic swelling studies; based on determining the increase in mass or volume of a crosslinked gel soaked in solvent. It is important to know the swelling behavior of gel, hydrogel and organohydrogels to be used in controlled release studies in physiological environments. Since the $\mathrm{pH}$ of the human body is not constant, at 2-12 $\mathrm{pH}$ balance range swelling analyzes were performed.

The change in percent swelling of gel, hydrogel and organogels as a function of solvent concentration in water-organic solvent mixtures was shown in Figure 2. After the AG gel was crosslinked, the IDwater absorption capacity increased in ratio[16, 20]. On the contrary, after the hydrogel added SAO, the IDwater absorption capacity approximately decreased in $40-52 \%$ for $p(A G-m)$ and $27-60 \%$ for $p(A G-g)$ the tapwater absorption capacity decreased in $37-57 \%$ for $p(A G-g)$ and $47-73 \%$ for $p(A G-m)$. p(AG-g-SAO) ${ }^{1}$ organohydrogel in DI water and ethanol/DI water medium swollen at a rate of about $83 \%$ and $77 \%$ of its dry mass, respectively. \% $S$ values of $p(A G-g-S A O)^{1}$ organohydrogel in acetone and gasoline media were approximately $7.6 \%$ and $2.4 \%$. In this situation; organohydrogels are associated with functional gruops in their structure and these gruops are; very prone to hydrogen bonding with water molecules. As a result of 
the said gruops forming hydrogen bonds with water molecules, more water molecules enter the organohydrogel structure and as a result, the organohydrogel swells more. On the other hand, swelling behavior in the polar environment; relates to protonation of functional gruops. Functional gruops formed in organohydrogel repel each other and cause organohydrogel pores to grow. Hereat; more solvent molecules enter the growing pores of organohydrogels, causing it to swell [25].

If we evaluate organohydrogels in terms of cross-linkers; GA cross-linked organohydrogels were found to have higher swelling values in different the solvent medium than MBA cross-linked organogels. When the swelling values in solvents are evaluated according to the amount of essential oil in organohydrogels; It was observed that the swelling values changed as the amount of essential oil increased. Swelling of organogels in different organic solvent-water mixtures can be controlled by the solvent composition. It is understood from the balance swelling graphs that the swelling behavior of organohydrogels is $\mathrm{pH}$ sensitive. This behavior; was an important feature of organohydrogels that release controlled drugs to be used especially in the stomach, intestine, skin and blood systems.

\section{Fourier Transform Infrared Spectroscopy (FT-IR) analysis}

Organohydrogels, AG, $p(A G-m), p(A G-g)$ were prepared by free radical polymerization in emulsion media and the FTIR spectra were shown in Figure 3 and explain in the literature [16, 20]. Sweet almond oil contained the band peak at $3600-3000 \mathrm{~cm}^{-1}$ belonging to the vibrtions of the $-\mathrm{OH}$ gruops, peak in 3007 $\mathrm{cm}^{-1}$ belonged $-\mathrm{CH}$, bands at $1742 \mathrm{~cm}^{-1}$ and $1650 \mathrm{~cm}^{-1}$ represented to $\mathrm{C}=\mathrm{O}$ and $-\mathrm{NH}$ vibrations. The peak in $2923 \mathrm{~cm}^{-1}$ belonged to the $-\mathrm{C}-\mathrm{H}$, peak in $1460 \mathrm{~cm}^{-1}$ belonged to the $\mathrm{CH}_{2}$ bands and $1375 \mathrm{~cm}^{-1}$ belonged to the carboxylates acid [26,27]. The new bonds and structural diversity at organohydrogels were demonstrated the existence of hydrogen-bond interaction. After the SAO got into the structure of the organohydrogel, the incoming bands from characteristic aromatic compounds (such as $2922 \mathrm{~cm}^{-1}-2853$, $\mathrm{cm}^{-1}, 1640 \mathrm{~cm}^{-1}$ and $1532 \mathrm{~cm}^{-1}$ ) exhibited high density, and the peaks appear to be deepened or expanded. Considering the peaks in the organohydrogel, the peak at $1742 \mathrm{~cm}^{-1}, 1375 \mathrm{~cm}^{-1}$ and $1650 \mathrm{~cm}^{-1}$ expanded and deepened, and the peak depth in the $1037 \mathrm{~cm}^{-1}$ increased. The change in these peaks indicated that SAO entered the structure of the organohydrogel.

\section{Antioxidant test}

Almond oil contains high amounts of phenolic compounds, an important class of antioxidants in the diet. Tocopherols are natural monophenols with antioxidant properties and are particularly rich sources of atocopherol. The antioxidant activity of SAO, AG, $p(A G-m), p(A G-g)$ and organohydrogels was given in table 4 as the gallic acid equivalent value. The SAO, AG, $p(A G-m), p(A G-g)$ and organohydrogels reduction capacity can determine it was antioxidant activity. When Table 4 was analyzed, reduction capacities of the SAO, AG, p (AG-m), p (AG-g) and organohydrogels could determine their antioxidant activity. When Table 4 was analyzed, it was observed that the power reduction due to the absorbents increased as the concentration of the substance increased. When these values were considered, organohydrogels shown higher antioxidant activity than the others. 


\section{Blood clotting and hemolysis tests}

Organohydrogels must meet certain criteria in order to be used in medical applications. Therefore, primary measures to determine the blood compatibility of organohydrogels are to determine the coagulation and destruction of red blood cells with the first adsorbed protein molecules on the surface. For this reason, the primary procedures to determine blood compatibility of an organohydrogel are coagulation $(\mathrm{BCl})$ and hemolysis tests. Organohydrogels blood compatibility analysis results were summarized in Figure 4. Hemolysis and blood coagulation analysis of gel, hydrogels and organohydrogels were performed and calculated. It was stated that the hemolysis rate was not hemolytic up to $5 \%$. Therefore, it can be said that organohydrogels were blood compatible at this rate. Hemolysis and blood clotting $(\mathrm{BCl})$ analysis of $A G, A G-m, A G-g, S A O$ and organohydrogels (at a concentration of 5 $\mathrm{mg} / \mathrm{mL}$ ) were performed, calculated and was given in Figure $4 \mathrm{a}, \mathrm{b}$.

\section{Ceftriaxone and Oxaliplatin release studies}

One of the most important issues in drug transportation systems research and development is the development of controlled drug release matrices. Controlled drug release matrices are the means by which a therapeutic agent is released over time in a certain area of the body and/or over a period of time. Organohydrogels are very suitable for such applications with their wide range of mechanical, physical and chemical properties. The structure of organohydrogels to be used for controlled drug release studies is a very important parameter. The surface on which the drug will retention and release will significantly affect the amount of attachment and rate of release.

The gel, hydrogel and organohydrogels loaded with Ceftriaxone and Oxaliplatin drugs were used in controlled drug release trials at $37.5 \mathrm{C}$ with four different $\mathrm{pH}$ media. Measurements were carried out at certain intervals until equilibrium in four different $\mathrm{pH}$ environments and results. It were given in Figure 5 and Table 5. AG, $\mathrm{p}(\mathrm{AG}-\mathrm{m})$ and $\mathrm{p}(\mathrm{AG}-\mathrm{g})$ maximum Ceftriaxone release were $3.54 \%$ at $\mathrm{pH} 7.4,12.59 \%$ at $\mathrm{pH}$ 8 and $13.67 \%$ at $\mathrm{pH} 7.4$, respectively. Moreover AG, $\mathrm{p}(\mathrm{AG}-\mathrm{m})$ and $\mathrm{p}(\mathrm{AG}-\mathrm{g})$ maximum Oxaliplatin release were $7.94 \%, 10.91 \%$, and $11.66 \%$ at $\mathrm{pH} 7.4$, respectively. When the organohydrogels were compared in terms of release amounts, the maximum release was obtained in the p(AG-g-SAO) organohydrogels. It was observed that p(AG-g-SAO) organohydrogel released $29 \%$ of Ceftriaxone and $100 \%$ of Oxaliplatin at $7.4 \mathrm{pH}$. It was found that the release of organohydrogels containing ceftriaxone was slow, and the total amount of drug released after 8 hours was low. These findings were interpreted as that Ceftriaxone in the organohydrogel structure can not only prolong the release but also protect Ceftriaxone from hydrolysis. As seen in Figure5, the amount of Oxaliplatin in the environment increased in the first 60 minutes, but then began to decrease over time. And almost all organohydrogels was observed to release $100 \%$ of Oxaliplatin in its structure within 10 hours. Unlike Ceftriaxone release from organohydrogels, Oxaliplatin release reached $100 \%$ release rate within 1 day. Moreover some of the other reported material at literature was HAP-2 (porosity of 2\% Hydroxyapatite)(34.78\% Ceftriaxone), HAP-4 (49.65\% Ceftriaxone), HAP-6 (64.65\% Ceftriaxone), HAP-8 (75.01\% Ceftriaxone) and HAP-10 (92.61\% Ceftriaxone)[28], Citrus-Pectin (CP) (97.2\% Ceftriaxone), CP:PVA 1:02 (97.7\% Ceftriaxone, 7 days), CP:PVA 1:04 (79.2\% Ceftriaxone, 7 
days), CP:PVA 1:06 (69.2\% Ceftriaxone, 7 days) [29], chitosan nanoparticles (98.4\%, pH4.5, Oxaliplatin) and chitosan nanoparticles (15.7\%, pH7.4, Oxaliplatin)[14], poly-lactic-co-glycolic acid-oxaliplatin microspheres (100\%, Oxaliplatin)[13], RG-503 (PLAGApolymer) (100\%, Oxaliplatin), 10\% PLAGAoligomer RG503 (90\%, Oxaliplatin), RG503 (80\%) and RG502 (20\%, Oxaliplatin)[15], MWCNTPEGOxaliplatin (80\%, Oxaliplatin, 7 days), MWCNTOxaliplatin (89\% Oxaliplatin, 5 days)[30], so on. The highest cumulative ceftriaxone release from organogels was observed in organogels synthesized by GA crosslinker. It was been seen from the results that ceftriaxone release can be controlled by changing the amount of sweet almond oil in organohydrogels.

When the Ceftriaxone release kinetics of the organohydrogels were examined, it was determined that the Ceftriaxone release of the organohydrogels synthesized with both types of crosslinkers conforms to the HM and KPM release kinetic model, given in Table 6. When Oxaliplatin release kinetics of organohydrogels were examined, it was observed that they fit the ZoM, HM and KPM release kinetics model., given in Table 7. When the results were examined, it was seen that the drug release of organohydrogels complies with Fick's law. For all organohydrogels, $n$ values were in the range of 0.1 to 0.5 . It was observed that all organohydrogels have decreased release values and $\mathrm{n}$ values.

\section{Conclusion}

The results achieved in the study were summarized as follows:

Within the scope of the presented study, preparation of Agar, Glycerol and Sweet almond oil-based organohydrogels loaded synthesized with different cross-linkers (glutaraldehyde (G) or methylene bis acrylamide (MBA)) and release studies of different drugs such as ceftriaxone and Oxaliplatin were examined in vitro conditions.

Organohydrogels A more useful drug-organohydrogel system was developed which is prepared in the form of cylindrical geometry and film and thus could release drugs in the stomach, intestine, skin and blood fluid system.

The synthesized organohydrogels; As a result of balance swelling studies in physiological solutions (2.0$12 \mathrm{pH}$ ) compared to body fluids, it has been observed that there are organohydrogels sensitive to $\mathrm{pH}$, which can be applied in gastric, intestinal, skin and blood fluid drug delivery systems.

Release studies of drug active molecules from Gel, hydrogels, and all organohydrogels which were loaded Ceftriaxone as a broad-spectrum antibiotic, and Oxaliplatin as drug component commonly used in cancer treatment were investigated 2.0, 5.5, 7.4 and $8.0 \mathrm{pH}$ environments. as a result, organohydrogels release behaviors were founded to be sensitive to $\mathrm{pH}$.

As a result; It can be suggested that all organohydrogels Ceftriaxone, Oxaliplatin and similar active substance molecules prepared as part of this study may be drug support materials that can be used in controlled release. 


\section{References}

[1] Y. Osada, J. Ping Gong, Y. Tanaka, Polymer Gels, Journal of Macromolecular Science, Part C: Polymer Reviews, 44 (2004) 87-112.

[2] T. Penzes, I. Csoka, I. Eros, Rheological analysis of the structural properties effecting the percutaneous absorption and stability in pharmaceutical organogels, Rheologica Acta, 43 (2004) 457-463.

[3] Y. Yang, S. Wang, H. Xu, C. Sun, X. Li, J. Zheng, Properties of topically applied organogels, Asian Journal of Pharmaceutical Sciences 3(2008) 175-183.

[4] A. Vintiloiu, J.C. Leroux, Organogels and their use in drug delivery-a review, J Control Release, 125 (2008) 179-192.

[5] N.K. Mujawar, S.L. Ghatage, V.C. Yeligar, Organogel: Factors and its importance, International Journal of Pharmaceutical, 4 (2014) 758-763.

[6] P. Terech, R.G. Weiss, Low molecular mass gelators of organic liquids and the properties of their gels, Chem. Rev., 97 (1997) 3133-3165.

[7] M.F. Balta, Fatty acid profiles for almond (Prunus amygdalus batsch) genotypes with different kernel taste and formation2, Iğdır Univ. J. Inst. Sci. \& Tech., 3 (2013) 17-24.

[8] Z. Ahmad, The uses and properties of almond oil, Complement Ther Clin Pract, 16 (2010) 2-10.

[9] D.A. Hyson, B.O. Schneeman, P.A. Davis, Almonds and almond oil have similar effects on plasma lipids and Idl oxidation in healthy men and women, American Society for Nutritional Sciences, 132 (2002) 703707.

[10] D.J. Jenkins, C.W. Kendall, A. Marchie, T.L. Parker, P.W. Connelly, W. Qian, J.S. Haight, D. Faulkner, E. Vidgen, K.G. Lapsley, G.A. Spiller, Dose response of almonds on coronary heart disease risk factors: blood lipids, oxidized low-density lipoproteins, lipoprotein(a), homocysteine, and pulmonary nitric oxide: a randomized, controlled, crossover trial, Circulation, 106 (2002) 1327-1332.

[11] A. A, A. G, A. B, Ceftriaxone: renal and biliary excretion and effect on the colon microflora., J Antimicrob Chemother, 10 (1982) 8.

[12] D. Wang, B. Hu, C. Hu, F. Zhu, X. Liu, J. Zhang, B. Wang, H. Xiang, Z. Cheng, Y. Xiong, Y. Zhao, Y. Li, X. Wang, Z. Peng, Clinical Characteristics of 138 Hospitalized Patients With 2019 Novel CoronavirusInfected Pneumonia in Wuhan, China, JAMA, 323 (2020) 1061-1069.

[13] J.Q. Li, S.L. Wang, F. Xu, Z.Y. Liu, R. Li, Therapeutic effectiveness of slow-release PLGA-oxaliplatin microsphere on human colorectal tumor-bearing mice, Anticancer Drugs, 21 (2010) 600-608. 
[14] R. Vivek, R. Thangam, V. Nipunbabu, T. Ponraj, S. Kannan, Oxaliplatin-chitosan nanoparticles induced intrinsic apoptotic signaling pathway: a "smart" drug delivery system to breast cancer cell therapy, Int J Biol Macromol, 65 (2014) 289-297.

[15] F. Lagarce, O. Cruaud, C. Deuschel, M. Bayssas, G. Griffon-Etienne, J.P. Benoit, Oxaliplatin loaded PLAGA microspheres: design of specific release profiles, International Journal of Pharmaceutics 242 (2002) 243-259.

[16] D. Alpaslan, T.E. Dudu, N. Aktaş, Synthesis and characterization of novel organo-hydrogel based agar, glycerol and peppermint oil as a natural drug carrier/release material, Materials Science and Engineering: C, 118 (2021).

[17] J. Zhang, B. Muirhead, M. Dodd, L. Liu, F. Xu, N. Mangiacotte, T. Hoare, H. Sheardown, An Injectable Hydrogel Prepared Using a PEG/Vitamin E Copolymer Facilitating Aqueous-Driven Gelation, Biomacromolecules, 17 (2016) 3648-3658.

[18] D. Alpaslan, T.E. Dudu, N. Sahiner, N. Aktasa, Synthesis and preparation of responsive poly(Dimethyl acrylamide/gelatin and pomegranate extract) as a novel food packaging material, Mater Sci Eng C Mater Biol Appl, 108 (2020) 110339.

[19] D. Alpaslan, Use of colorimetric hydrogel as an indicator for food packaging applications, Bulletin of Materials Science, 42 (2019) 1-11.

[20] T. Olak, A. Turan, D. Alpaslan, T.E. Dudu, N. Aktaş, Developing poly(Agar-co-Glycerol-co-Thyme Oil) based organo-hydrogels for the controlled drug release applications, Journal of Drug Delivery Science and Technology, 60 (2020).

[21] R.J.A.J. Singleton V L, Colorimetry of total phenolics with phosphomolybdic-phosphotungstic acid reagents., American journal of Enology and Viticulture,, 16 (1965) 12.

[22] D. Alpaslan, T.E. Dudu, N. Aktaş, Synthesis, Characterization and Modification of Novel Food Packaging Material from Dimethyl acrylamide/Gelatin and Purple Cabbage Extract, MANAS Journal of Engineering, 6 (2018) 15-33.

[23] D. Alpaslan, T.E. Dudu, N. Aktas, Synthesis of smart food packaging from poly(gelatin-co-dimethyl acrylamide)/citric acid-red apple peel extract, Soft Materials, (2021) 1-14.

[24] W.G.B. Obert E. Childs, The steady-state kinetics of peroxidase with 2, 2'-azino-di-(3-ethylbenzthiazoline-6-sulphonic acid) as chromogen., Biochemical Journal, 145 (1975) 10.

[25] Ö.B. Üzüm, E. Karadağ, Equilibrium Swelling Studies of Chemically Cross-Linked Highly Swollen Acrylamide-Sodium Acrylate Hydrogels in Various Water-Solvent Mixtures, Polymer-Plastics Technology and Engineering, 49 (2010) 609-616. 
[26] S. Sharma, N. raj, FTIR Spectroscopic Characterisation of Almond Varieties (Prunus dulcis) from Himachal Pradesh (India), International Journal of Current Microbiology and Applied Sciences, 7 (2018) 887-898.

[27] A. Beltrán Sanahuja, M.S. Prats Moya, S.E. Maestre Pérez, N. Grané Teruel, M.L. Martín Carratalá, Classification of Four Almond Cultivars Using Oil Degradation Parameters Based on FTIR and GC Data, Journal of the American Oil Chemists' Society, 86 (2008) 51-58.

[28] Z.N. Al-Sokanee, A.A. Toabi, M.J. Al-Assadi, E.A. Alassadi, The drug release study of ceftriaxone from porous hydroxyapatite scaffolds, AAPS PharmSciTech, 10 (2009) 772-779.

[29] L.A. Badykova, A.A. Fatykhov, R.K. Mudarisova, Polymer composite films based on citrus pectin for controlled delivery of Ceftriaxone, Russian Journal of General Chemistry, 84 (2014) 2004-2008.

[30] L. Wu, C. Man, H. Wang, X. Lu, Q. Ma, Y. Cai, W. Ma, PEGylated multi-walled carbon nanotubes for encapsulation and sustained release of oxaliplatin, Pharm Res, 30 (2013) 412-423.

\section{Tables}

Table 1 Codes of different organohydrogel

\begin{tabular}{cc}
\hline Gel & Code \\
\hline Agar-Glycerol & AG \\
\hline Hydrogel & Code \\
\hline poly (Agar-Co-Glycerol)/MBA & $\mathrm{p}(\mathrm{AG}-\mathrm{m})$ \\
\hline poly (Agar-co-Glycerol)/GA & $\mathrm{p}(\mathrm{AG}-\mathrm{g})$ \\
\hline Organo-ydrogel & Code \\
\hline poly (Agar-co-Glycerol-co-Sweet Almond Oil)/MBA-1 & $\mathrm{p}(\mathrm{AG}-\mathrm{m}-\mathrm{SAO})^{1}$ \\
\hline poly (Agar-co-Glycerol-co-Sweet Almond Oil)/MBA-2 & $\mathrm{p}(\mathrm{AG}-\mathrm{m}-\mathrm{SAO})^{2}$ \\
\hline poly (Agar-co-Glycerol-co-Sweet Almond Oil)/MBA-3 & $\mathrm{p}(\mathrm{AG}-\mathrm{m}-\mathrm{SAO})^{3}$ \\
\hline poly (Agar-co-Glycerol-co-Sweet Almond Oil)/GA-1 & $\mathrm{p}(\mathrm{AG}-\mathrm{g}-\mathrm{SAO})^{1}$ \\
\hline poly (Agar-co-Glycerol-co-Sweet Almond Oil/GA-2 & $\mathrm{p}(\mathrm{AG}-\mathrm{g}-\mathrm{SAO})^{2}$ \\
\hline poly (Agar-co-Glycerol-co-Sweet Almond Oil)/GA-3 & $\mathrm{p}(\mathrm{AG}-\mathrm{g}-\mathrm{SAO})^{3}$ \\
\hline
\end{tabular}

Table 2 Compositions and codes of different organohydrogel 


\begin{tabular}{ccccc}
\hline Agar & Glycerol & SAO & Crosslinker & Code \\
\hline $2 \%-2 \mathrm{~mL}$ & $0.04 \mathrm{~mL}$ & -- & -- & AG \\
$2 \%-2 \mathrm{~mL}$ & $0.04 \mathrm{~mL}$ & --- & MBA & p(AG-m) \\
\hline $2 \%-2 \mathrm{~mL}$ & $0.04 \mathrm{~mL}$ & --- & GA & p(AG-g) \\
\hline $2 \%-2 \mathrm{~mL}$ & $0.04 \mathrm{~mL}$ & $0.1 \mathrm{~mL}$ & MBA & p(AG-m-SAO) \\
\hline $2 \%-2 \mathrm{~mL}$ & $0.04 \mathrm{~mL}$ & $0.2 \mathrm{~mL}$ & MBA & p(AG-m-SAO) ${ }^{2}$ \\
$2 \%-2 \mathrm{~mL}$ & $0.04 \mathrm{~mL}$ & $0.3 \mathrm{~mL}$ & MBA & p(AG-m-SAO) ${ }^{3}$ \\
\hline$\%-2 \mathrm{~mL}$ & $0.04 \mathrm{~mL}$ & $0.1 \mathrm{~mL}$ & GA & p(AG-g-SAO) $^{1}$ \\
$2 \%-2 \mathrm{~mL}$ & $0.04 \mathrm{~mL}$ & $0.2 \mathrm{~mL}$ & GA & p(AG-g-SAO) $^{2}$ \\
$2 \%-2 \mathrm{~mL}$ & $0.04 \mathrm{~mL}$ & $0.3 \mathrm{~mL}$ & GA & (AG-g-SAO) $^{3}$ \\
\hline
\end{tabular}

3. Mathematical models for drug release.

\begin{tabular}{|c|c|c|c|}
\hline Model & Mathematical Equation & Release Mechanism & Codes \\
\hline Zero order kinetic model & & Diffusion Mechanism & $\overline{\mathrm{ZoM}}$ \\
\hline First order kinetic model & & $\begin{array}{c}\text { Fick's first law, diffusion } \\
\text { Mechanism }\end{array}$ & FoM \\
\hline Higuchi Model & & $\begin{array}{c}\text { Diffusion medium based } \\
\text { Mechanism in Fick's first law }\end{array}$ & $\mathrm{HM}$ \\
\hline Korsemeyer-Peppas Model & & $\begin{array}{l}\text { Semi empirical model, } \\
\text { diffusion-based mechanism }\end{array}$ & KPM \\
\hline
\end{tabular}

$\mathrm{C}_{\mathrm{r}}$ is concentration of urea release in time $\mathrm{t}(\mathrm{mg} / \mathrm{L}) ; \mathrm{C}_{0}$ is the initial concentration of urea in the solution (most times, $\left.\mathrm{C}_{0}=0\right)(\mathrm{mg} / \mathrm{L}) ; \mathrm{k}_{0}$ is the zero order release constant expressed in units of concentration/time (mg/(L.min)); $t$ is time $(\mathrm{min}) ; \mathrm{k}_{1}$ is the first order release constant (1/min); $\mathrm{C}_{\infty}$ is concentration of fertilizer release in equilibrium (mg/L); $\mathrm{k}_{\mathrm{H}}$ is Higuchi release rate constant (1/); $\mathrm{k}_{\mathrm{KP}}$ is Korsmeyer-Peppas release rate constant; $\mathrm{n}$ is release exponent which is indicative of the transport mechanism $\left(\mathrm{M}_{\mathrm{t}} / \mathrm{M}_{\infty}<0.6\right.$ should only be used.

! Total phenol content values.

\begin{tabular}{|c|c|}
\hline Substance & Total phenol (mg) \\
\hline \multicolumn{2}{|l|}{ Organohydrogel } \\
\hline $\mathrm{p}(\mathrm{AG}-\mathrm{m}-\mathrm{SAO})^{1}$ & 463 \\
\hline $\mathrm{p}(\mathrm{AG}-\mathrm{m}-\mathrm{SAO})^{2}$ & 462 \\
\hline $\mathrm{p}(\mathrm{AG}-\mathrm{m}-\mathrm{SAO})^{3}$ & 527 \\
\hline$p(A G-g-S A O)^{1}$ & 594 \\
\hline $\mathrm{p}(\mathrm{AG}-\mathrm{g}-\mathrm{SAO})^{2}$ & 918 \\
\hline $\mathrm{p}(\mathrm{AG}-\mathrm{g}-\mathrm{SAO})^{3}$ & 941 \\
\hline \multicolumn{2}{|l|}{ Oil } \\
\hline Sweet Almond Oil & 959 \\
\hline
\end{tabular}

; Ceftriaxone Oxaliplatin \% release values. 


\begin{tabular}{lcccc|c}
\cline { 2 - 6 } & \multicolumn{4}{c|}{ Ceftriaxone } & Oxaliplatin \\
\cline { 2 - 6 } & pH 2.0 & pH 5.5 & pH 7.4 & pH 8.0 & pH 7.4 \\
\hline & \multicolumn{3}{c}{ Release \% } & Release \% \\
\hline p(AG-m-SAO) $^{1}$ & 8.43 & 14.00 & 20.00 & 17.01 & 100 \\
p(AG-m-SAO) $^{2}$ & 8.51 & 15.96 & 20.57 & 16.50 & 100 \\
p(AG-m-SAO) $^{3}$ & 9.83 & 13.03 & 19.60 & 15.97 & 100 \\
p(AG-g-SAO) $^{1}$ & 16.92 & 12.68 & 26.07 & 21.22 & 100 \\
p(AG-g-SAO) $^{2}$ & 21.29 & 15.59 & 24.73 & 20.22 & 100 \\
p(AG-g-SAO) $^{3}$ & 21.67 & 17.09 & 29.34 & 24.58 & 100 \\
\hline
\end{tabular}

; Release kinetic and mechanism of Ceftriaxone release. 


\begin{tabular}{|c|c|c|c|c|c|c|c|c|c|c|c|}
\hline \multicolumn{2}{|c|}{ (AG-m-SAO) ${ }^{1}$} & 2.0 & 5.5 & 7.4 & 8.0 & \multicolumn{2}{|c|}{$\mathrm{p}(\mathrm{AG}-\mathrm{g}-\mathrm{SAO})^{1}$} & 2.0 & 5.5 & 7.4 & 8.0 \\
\hline \multirow[t]{3}{*}{$\overline{\text { ZoM }}$} & $\mathrm{C}_{\mathrm{o}}$ & 1.785 & 1.612 & 2.235 & 2.066 & \multirow[t]{3}{*}{ ZoM } & \multirow{3}{*}{$\begin{array}{l}\mathrm{C}_{\mathrm{o}} \\
\mathrm{k}_{\mathrm{o}} \\
\mathrm{R}^{2}\end{array}$} & 1.802 & 1.602 & 2.616 & 2.019 \\
\hline & $\mathbf{k}_{\mathbf{o}}$ & -0.003 & -0.005 & -0.006 & -0.005 & & & -0.008 & -0.004 & -0.008 & -0.006 \\
\hline & $\mathrm{R}^{2}$ & 0.800 & 0.985 & 0.779 & 0.817 & & & 0.823 & 0.847 & 0.711 & 0.762 \\
\hline \multirow[t]{3}{*}{$\overline{\text { FoM }}$} & $\mathrm{C}_{\mathrm{o}}$ & 2.080 & 1.886 & 15.007 & 11.057 & \multirow[t]{3}{*}{ FoM } & \multirow{3}{*}{$\begin{array}{l}\mathrm{C}_{\mathrm{o}} \\
\mathrm{k}_{1} \\
\mathrm{R}^{2}\end{array}$} & 1.186 & 0.803 & 3.909 & 2.909 \\
\hline & $\mathbf{k}_{1}$ & -0.001 & -0.001 & -0.004 & -0.004 & & & -0.001 & -0.001 & -0.004 & -0.003 \\
\hline & $\mathrm{R}^{2}$ & 0.732 & 0.635 & 0.900 & 0.851 & & & 0.800 & 0.770 & 0.909 & 0.963 \\
\hline \multirow[t]{2}{*}{ HM } & $\mathbf{k}_{\mathrm{h}}$ & 0.034 & 0.017 & 0.028 & 0.028 & \multirow[t]{2}{*}{$\mathrm{HM}$} & \multirow{2}{*}{$\begin{array}{l}\mathbf{k}_{\mathrm{h}} \\
\mathrm{R}^{2}\end{array}$} & 0.048 & 0.025 & 0.022 & 0.245 \\
\hline & $\mathrm{R}^{2}$ & 0.997 & 0.918 & 0.959 & 0.959 & & & 0.990 & 0.909 & 0.991 & 0.993 \\
\hline \multirow[t]{3}{*}{$\overline{\mathrm{KPM}}$} & n & 0.219 & 0.286 & 0.239 & 0.267 & \multirow[t]{3}{*}{ KPM } & \multirow{3}{*}{$\begin{array}{c}\mathrm{n} \\
\mathrm{kkp} \\
\mathrm{R}^{2}\end{array}$} & 0.414 & 0.394 & 0.338 & 0.359 \\
\hline & kkp & 4.850 & 9.640 & 7.475 & 8.909 & & & 14.701 & 14.644 & 10.514 & 13.194 \\
\hline & $\mathrm{R}^{2}$ & 0.947 & 0.923 & 0.940 & 0.934 & & & 0.923 & 0.899 & 0.937 & 0.927 \\
\hline \multicolumn{2}{|c|}{$\underline{(\text { AG-m-SAO })^{2}}$} & 2.0 & 5.5 & 7.4 & 8.0 & \multicolumn{2}{|c|}{$\mathrm{p}(\mathrm{AG}-\mathrm{g}-\mathrm{SAO})^{2}$} & 2.0 & 5.5 & 7.4 & 8.0 \\
\hline \multirow[t]{3}{*}{ ZoM } & $\mathrm{C}_{\mathrm{o}}$ & 1.287 & 0.593 & 1.319 & 2.133 & \multirow[t]{3}{*}{ ZoM } & \multirow{3}{*}{$\begin{array}{l}\mathrm{C}_{\mathrm{o}} \\
\mathrm{k}_{\mathrm{o}} \\
\mathrm{R}^{2}\end{array}$} & 1.930 & 1.723 & 2.210 & 1.817 \\
\hline & $\mathbf{k}_{\mathbf{o}}$ & -0.002 & -0.005 & -0.003 & -0.005 & & & -0.006 & -0.003 & -0.004 & -0.004 \\
\hline & $\mathrm{R}^{2}$ & 0.940 & 0.997 & 0.870 & 0.809 & & & 0.908 & 0.930 & 0.867 & 2.019 \\
\hline \multirow[t]{3}{*}{ FoM } & $\mathrm{C}_{\mathrm{o}}$ & 1.408 & 1.140 & 2.620 & 11.844 & \multirow[t]{3}{*}{ FoM } & \multirow{3}{*}{$\begin{array}{l}\mathrm{C}_{\mathrm{o}} \\
\mathrm{k}_{1} \\
\mathrm{R}^{2}\end{array}$} & 0.716 & 0.665 & 2.210 & 1.996 \\
\hline & $\mathbf{k}_{1}$ & -0.001 & -0.003 & -0.006 & -0.005 & & & -0.002 & -0.001 & -0.004 & -0.003 \\
\hline & $\mathrm{R}^{2}$ & 0.980 & 0.946 & 0.885 & 0.932 & & & 0.800 & 0.908 & 0.867 & 0.942 \\
\hline \multirow[t]{2}{*}{$\mathrm{HM}$} & $\mathbf{k}_{\mathrm{h}}$ & 0.039 & 0.012 & 0.024 & 0.028 & \multirow[t]{2}{*}{ HM } & \multirow{2}{*}{$\begin{array}{l}\mathbf{k}_{\mathrm{h}} \\
\mathrm{R}^{2}\end{array}$} & 0.036 & 0.021 & 0.219 & 0.219 \\
\hline & $\mathrm{R}^{2}$ & 0.996 & 0.986 & 0.952 & 0.959 & & & 0.997 & 0.976 & 0.992 & 0.992 \\
\hline $\mathrm{KPM}$ & $\mathrm{n}$ & 0.234 & 0.632 & 0.374 & 0.229 & KPM & $\mathrm{n}$ & 0.294 & 0.307 & 0.235 & 0.216 \\
\hline & kkp & 6.399 & 80.310 & 20.545 & 5.936 & & kkp & 9.101 & 9.740 & 6.352 & 5.645 \\
\hline & $\mathrm{R}^{2}$ & 0.971 & 0.996 & 0.717 & 0.912 & & $\mathrm{R}^{2}$ & 0.940 & 0.993 & 0.970 & 0.944 \\
\hline (AG-n & $\mathrm{AO})^{3}$ & 2.0 & 5.5 & 7.4 & 8.0 & $p(A G-g$ & $A O)^{3}$ & 2.0 & 5.5 & 7.4 & 8.0 \\
\hline ZoM & $\mathrm{C}_{\mathrm{o}}$ & 0.948 & 0.614 & 1.265 & 1.236 & ZoM & $\mathrm{C}_{\mathrm{o}}$ & 1.582 & 1.011 & 1.223 & 0.713 \\
\hline & $\mathbf{k}_{\mathbf{o}}$ & -0.004 & -0.004 & -0.006 & -0.006 & & $\mathbf{k}_{\mathbf{o}}$ & -0.009 & -0.006 & -0.008 & -0.006 \\
\hline & $\mathrm{R}^{2}$ & 0.755 & 0.923 & 0.746 & 0.814 & & $\mathrm{R}^{2}$ & 0.828 & 0.902 & 0.895 & 0.931 \\
\hline FoM & $\mathrm{C}_{\mathrm{o}}$ & 1.553 & 1.068 & 4.593 & 6.132 & FoM & $\mathrm{C}_{\mathrm{o}}$ & 1.146 & 0.583 & 2.178 & 1.440 \\
\hline & $\mathbf{k}_{1}$ & -0.001 & -0.002 & -0.005 & -0.004 & & $\mathbf{k}_{1}$ & -0.001 & -0.002 & -0.003 & -0.005 \\
\hline & $\mathrm{R}^{2}$ & 0.814 & 0.946 & 0.825 & 0.953 & & $\mathrm{R}^{2}$ & 0.840 & 0.882 & 0.968 & 0.977 \\
\hline HM & $\mathbf{k}_{\mathbf{h}}$ & 0.025 & 0.017 & 0.025 & 0.025 & HM & $\mathbf{k}_{\mathrm{h}}$ & 0.022 & 0.027 & -0.130 & -0.130 \\
\hline & $\mathrm{R}^{2}$ & 0.944 & 0.969 & 0.953 & 0.953 & & $\mathrm{R}^{2}$ & 0.915 & 0.982 & 0.994 & 0.994 \\
\hline$\overline{\mathrm{KPM}}$ & $\mathbf{n}$ & 0.229 & 0.418 & 0.328 & 0.328 & KPM & $\mathbf{n}$ & 0.392 & 0.479 & 0.427 & 0.554 \\
\hline & kkp & 5.848 & 1.000 & 12.569 & 10.251 & & kkp & 13.005 & 26.441 & 20.164 & 51.172 \\
\hline & $\mathrm{R}^{2}$ & 0.943 & 0.952 & 0.841 & 0.959 & & $\mathrm{R}^{2}$ & 0.964 & 0.985 & 0.968 & 0.960 \\
\hline
\end{tabular}

Fickian diffusion mechanism $\mathrm{n} \leq 0.45$, non-Fickian (anomalous) diffusion mechanism. $0.45<\mathrm{n}<0.89$

' Release kinetic and mechanism of Oxaliplatin release. 


\begin{tabular}{|c|c|c|c|c|c|}
\hline \multicolumn{2}{|c|}{$\mathrm{p}(\mathrm{AG}-\mathrm{m}-\mathrm{SAO})^{1}$} & \multirow{2}{*}{\begin{tabular}{|c|}
7.4 \\
1.512 \\
\end{tabular}} & \multicolumn{2}{|c|}{$\mathrm{p}(\mathrm{AG}-\mathrm{g}-\mathrm{SAO})^{1}$} & \multirow{4}{*}{$\begin{array}{c}7.4 \\
2.113 \\
-0.007 \\
0.658\end{array}$} \\
\hline ZoM & $\mathrm{C}_{\mathrm{o}}$ & & \multirow[t]{3}{*}{ ZoM } & $\mathrm{C}_{\mathrm{o}}$ & \\
\hline & $\mathbf{k}_{\mathrm{o}}$ & -0.006 & & $\mathbf{k}_{\mathbf{o}}$ & \\
\hline & $\mathrm{R}^{2}$ & 0.713 & & $\mathrm{R}^{2}$ & \\
\hline \multirow[t]{3}{*}{ FoM } & $\mathrm{C}_{\mathrm{o}}$ & 1.640 & \multirow[t]{3}{*}{ FoM } & $\mathrm{C}_{\mathrm{o}}$ & 2.004 \\
\hline & $\mathbf{k}_{1}$ & -0.018 & & $\mathbf{k}_{1}$ & -0.008 \\
\hline & $\mathrm{R}^{2}$ & 0.784 & & $\mathbf{R}^{2}$ & 0.718 \\
\hline \multirow[t]{2}{*}{ HM } & $\mathbf{k}_{\mathrm{h}}$ & 0.008 & \multirow[t]{2}{*}{$\mathrm{HM}$} & $\mathbf{k}_{\mathrm{h}}$ & 0.022 \\
\hline & $\mathrm{R}^{2}$ & 0.955 & & $\mathrm{R}^{2}$ & 0.991 \\
\hline \multirow[t]{3}{*}{$\overline{\mathrm{KPM}}$} & $\mathrm{n}$ & 0.392 & \multirow[t]{3}{*}{ KPM } & $\mathrm{n}$ & -2.255 \\
\hline & kkp & 0.091 & & kkp & -0.313 \\
\hline & $\mathbf{R}^{2}$ & 0.841 & & $\mathrm{R}^{2}$ & 0.872 \\
\hline \multicolumn{2}{|c|}{$\mathrm{p}(\mathrm{AG}-\mathrm{m}-\mathrm{SAO})^{2}$} & 7.4 & \multicolumn{2}{|c|}{$\mathrm{p}(\mathrm{AG}-\mathrm{g}-\mathrm{SAO})^{2}$} & 7.4 \\
\hline \multirow[t]{3}{*}{ ZoM } & $\mathrm{C}_{\mathrm{o}}$ & 1.494 & \multirow[t]{3}{*}{ ZoM } & $\mathrm{C}_{\mathrm{o}}$ & 2.143 \\
\hline & $\mathbf{k}_{\mathrm{o}}$ & -0.003 & & $\mathbf{k}_{\mathbf{0}}$ & -0.004 \\
\hline & $\mathrm{R}^{2}$ & 0.728 & & $\mathbf{R}^{2}$ & 0.831 \\
\hline \multirow[t]{3}{*}{ FoM } & $\mathrm{C}_{\mathrm{o}}$ & 1.975 & \multirow[t]{3}{*}{ FoM } & $\mathrm{C}_{\mathrm{o}}$ & 2.143 \\
\hline & $\mathbf{k}_{1}$ & -0.001 & & $\mathbf{k}_{1}$ & -0.004 \\
\hline & $\mathrm{R}^{2}$ & 0.885 & & $\mathrm{R}^{2}$ & 0.831 \\
\hline \multirow[t]{2}{*}{$\mathrm{HM}$} & $\mathbf{k}_{\mathrm{h}}$ & 0.024 & \multirow[t]{2}{*}{$\mathrm{HM}$} & $\mathbf{k}_{\mathrm{h}}$ & 0.219 \\
\hline & $\mathrm{R}^{2}$ & 0.952 & & $\mathrm{R}^{2}$ & 0.992 \\
\hline \multirow[t]{3}{*}{$\overline{\mathrm{KPM}}$} & $\mathrm{n}$ & 0.378 & \multirow[t]{3}{*}{ KPM } & $\mathrm{n}$ & -1.835 \\
\hline & kkp & 0.071 & & kkp & -0.238 \\
\hline & $\mathrm{R}^{2}$ & 0.929 & & $\mathrm{R}^{2}$ & 0.969 \\
\hline \multicolumn{2}{|c|}{$\mathrm{p}(\mathrm{AG}-\mathrm{m}-\mathrm{SAO})^{3}$} & 7.4 & \multicolumn{2}{|c|}{$\mathrm{p}(\mathrm{AG}-\mathrm{g}-\mathrm{SAO})^{3}$} & 7.4 \\
\hline \multirow[t]{3}{*}{ ZoM } & $\mathrm{C}_{\mathrm{o}}$ & 0.842 & \multirow[t]{3}{*}{ ZoM } & $\mathrm{C}_{\mathrm{o}}$ & 0.496 \\
\hline & $\mathbf{k}_{\mathbf{o}}$ & -0.006 & & $\mathbf{k}_{\mathbf{o}}$ & -0.006 \\
\hline & $\mathrm{R}^{2}$ & 0.839 & & $\mathrm{R}^{2}$ & 0.953 \\
\hline \multirow[t]{3}{*}{ FoM } & $\mathrm{C}_{\mathrm{o}}$ & 3.453 & \multirow[t]{3}{*}{ FoM } & $\mathrm{C}_{\mathrm{o}}$ & 3.437 \\
\hline & $\mathbf{k}_{1}$ & -0.009 & & $\mathbf{k}_{1}$ & -0.003 \\
\hline & $\mathbf{R}^{2}$ & 0.945 & & $\mathbf{R}^{2}$ & 0.884 \\
\hline \multirow[t]{2}{*}{ HM } & $\mathrm{k}_{\mathrm{h}}$ & 0.025 & $\mathrm{HM}$ & $\mathbf{k}_{\mathrm{h}}$ & -0.130 \\
\hline & $\mathbf{R}^{2}$ & 0.953 & & $\mathbf{R}^{2}$ & 0.994 \\
\hline KPM & $\mathrm{n}$ & 0.371 & KPM & $\mathrm{n}$ & -1.498 \\
\hline & kkp & 0.057 & & kkp & -0.199 \\
\hline & $\mathrm{R}^{2}$ & 0.954 & & & 0.905 \\
\hline
\end{tabular}

Fickian diffusion mechanism $\mathrm{n} \leq 0.45$, non-Fickian (anomalous) diffusion mechanism. $0.45<\mathrm{n}<0.89$

\section{Figures}




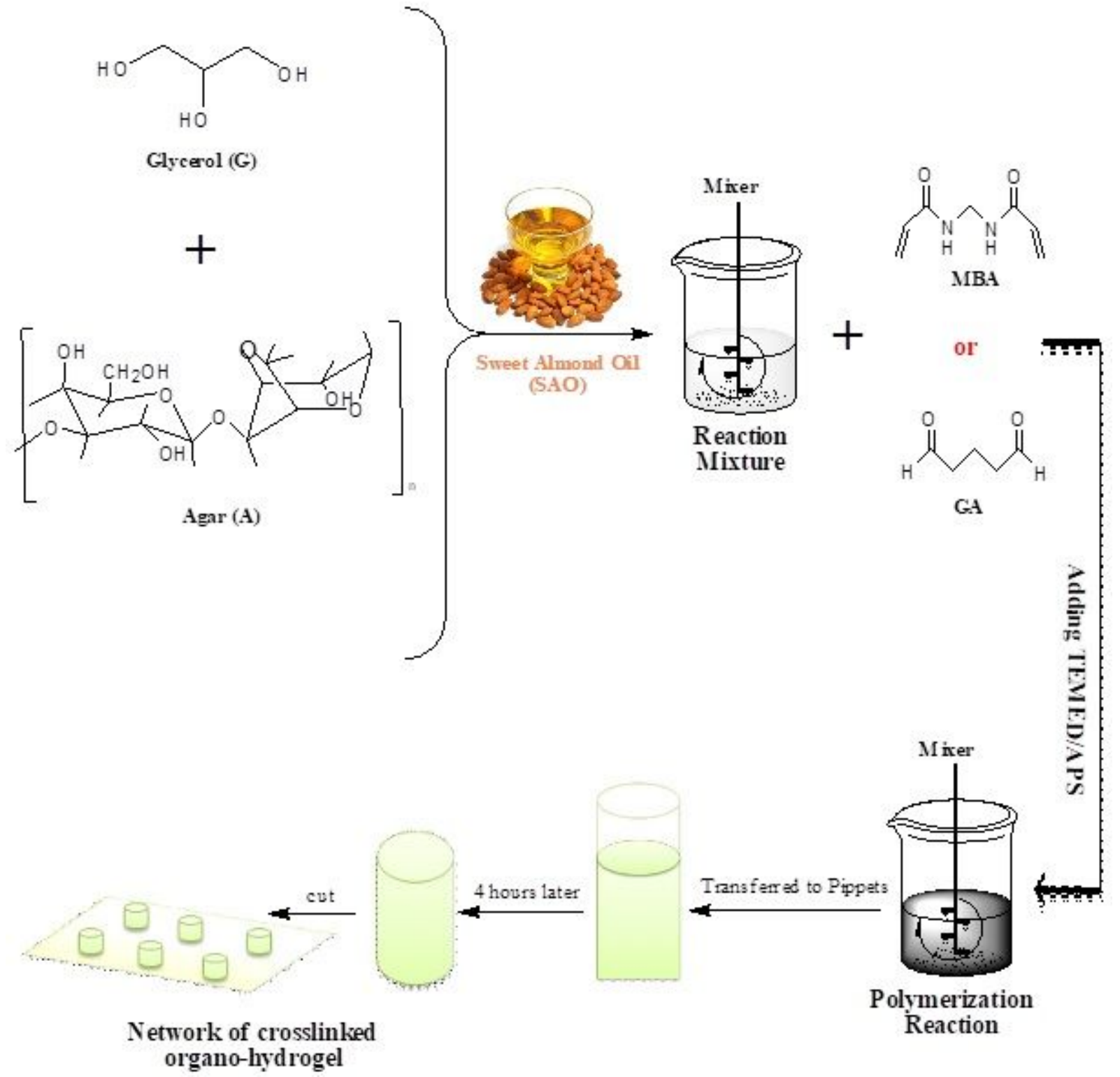

Figure 1

Synthesis and schematic presentation of organohydrogels. 

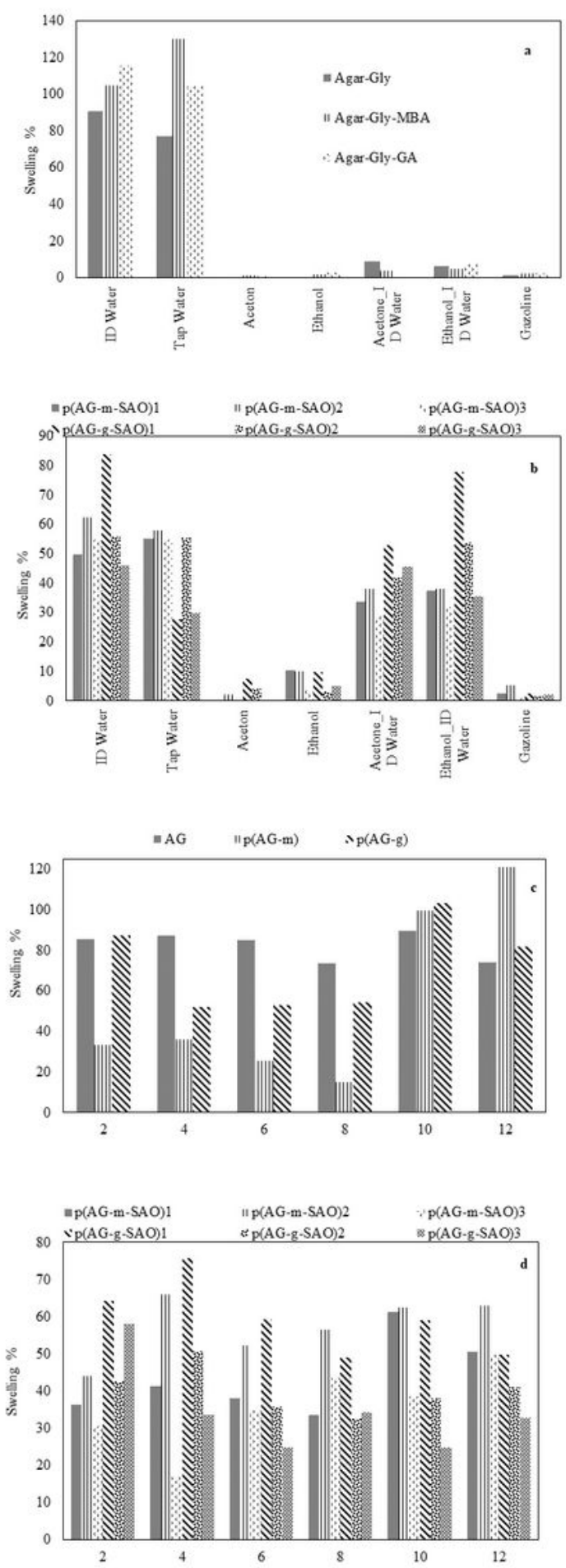

Figure 2

Percent swelling degree of the (a)AG, $p(A G-m), p(A G-g)$ and (b) organohydrogels with time in ID water, tap water, ethanol, acetone, ethanol/ID water (1:1), acetone/ID water (1:1) and gasoline. Swelling \% of the (c) AG, $\mathrm{p}(\mathrm{AG}-\mathrm{m}), \mathrm{p}(\mathrm{AG}-\mathrm{g})$ and $(\mathrm{d})$ organohydrogels as a function of $2.0-12 \mathrm{pH}$ ( $\mathrm{pH}$ is adjusted by the addition of $0.1 \mathrm{M} \mathrm{HCl}, 0.1 \mathrm{M} \mathrm{NaOH}$ ). 

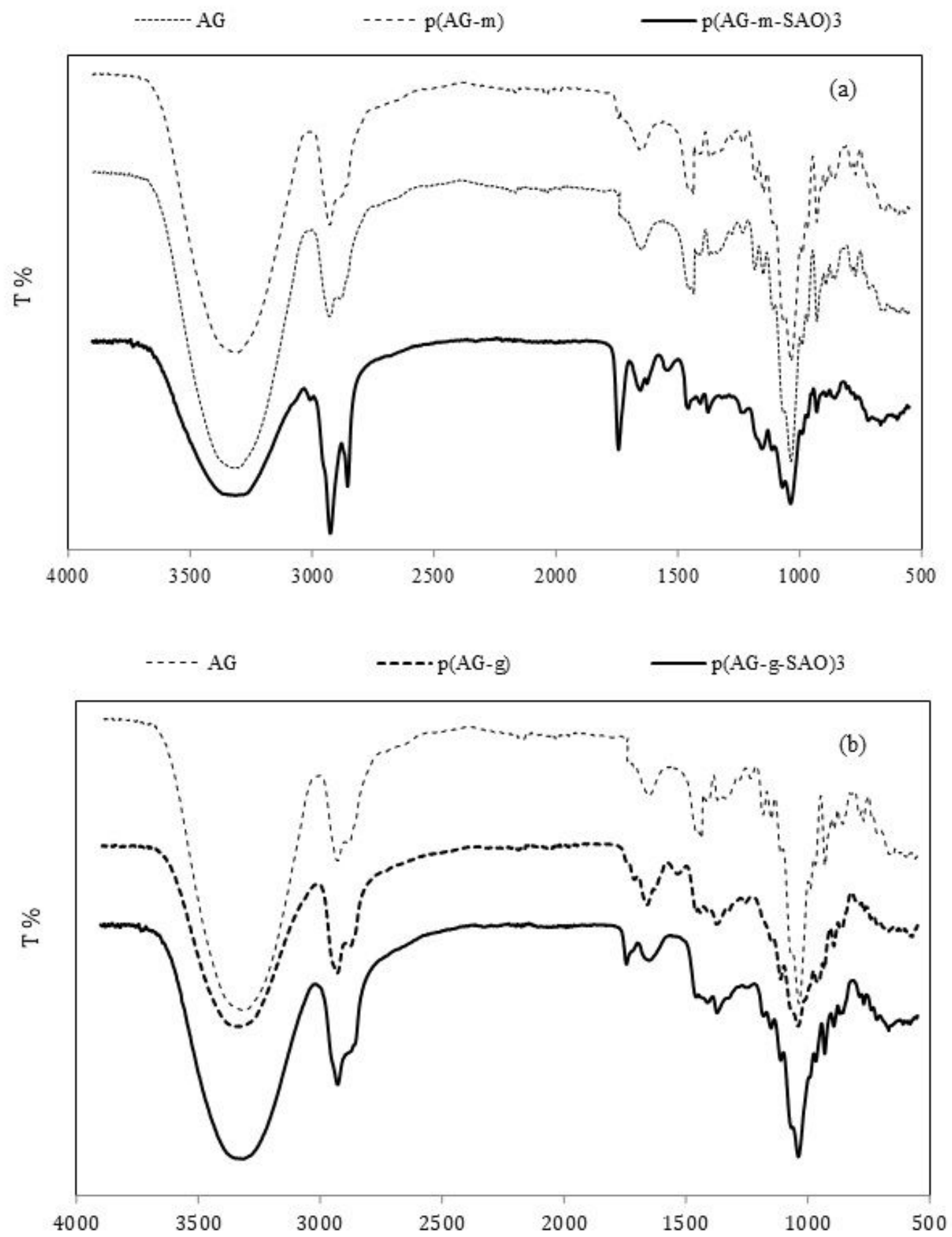

Figure 3

FT-IR Spectra of (a) AG, p(AG-m), and p(AG-m-SAO)3, (b) AG, p(AG-g) and p(AG-g-SAO)3 organohydrogels 

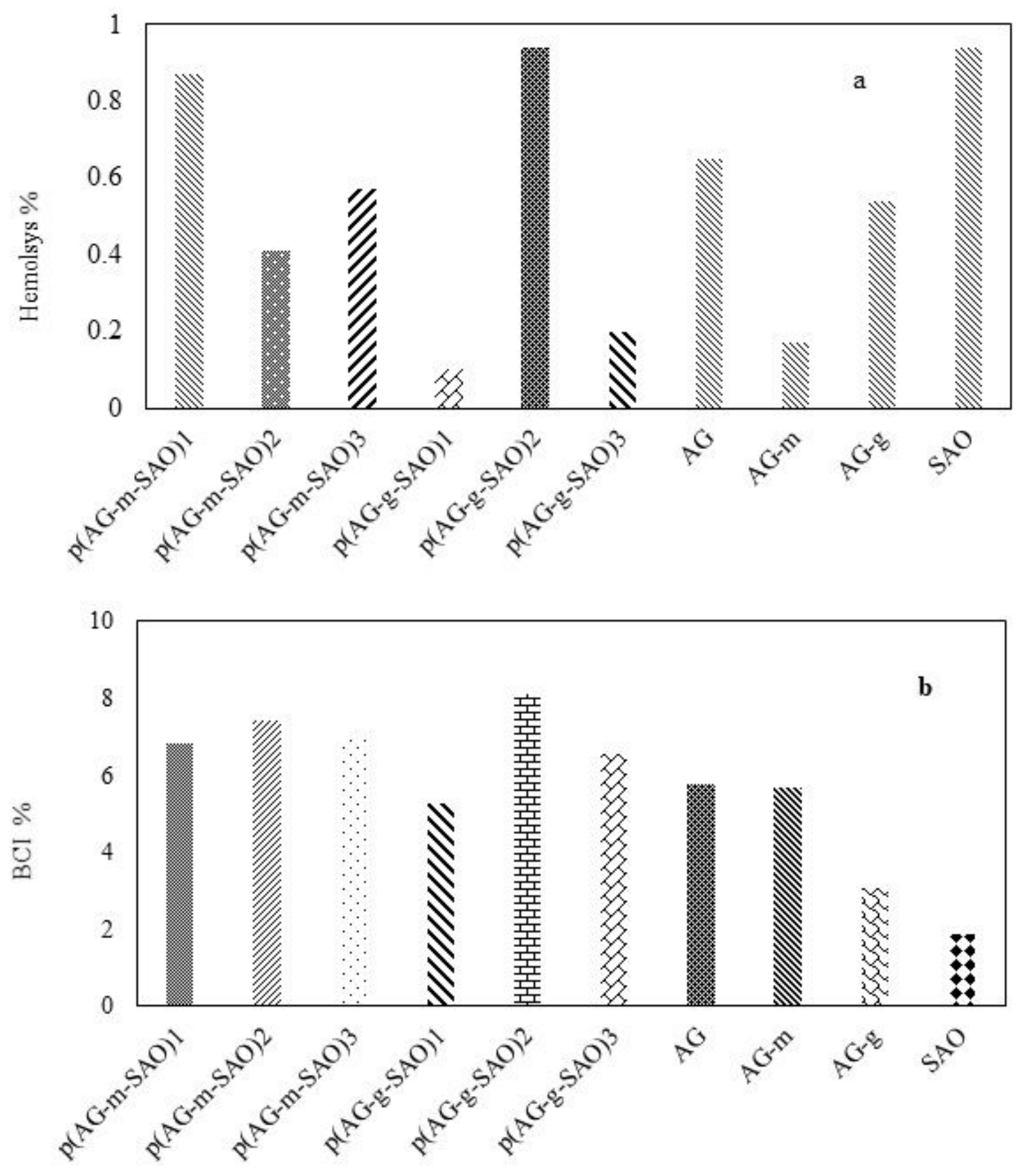

Figure 4

Blood combability of the AG, p(AG-m), p(AG-g) and organohydrogels (a) hemolysis (b) blood clotting. 

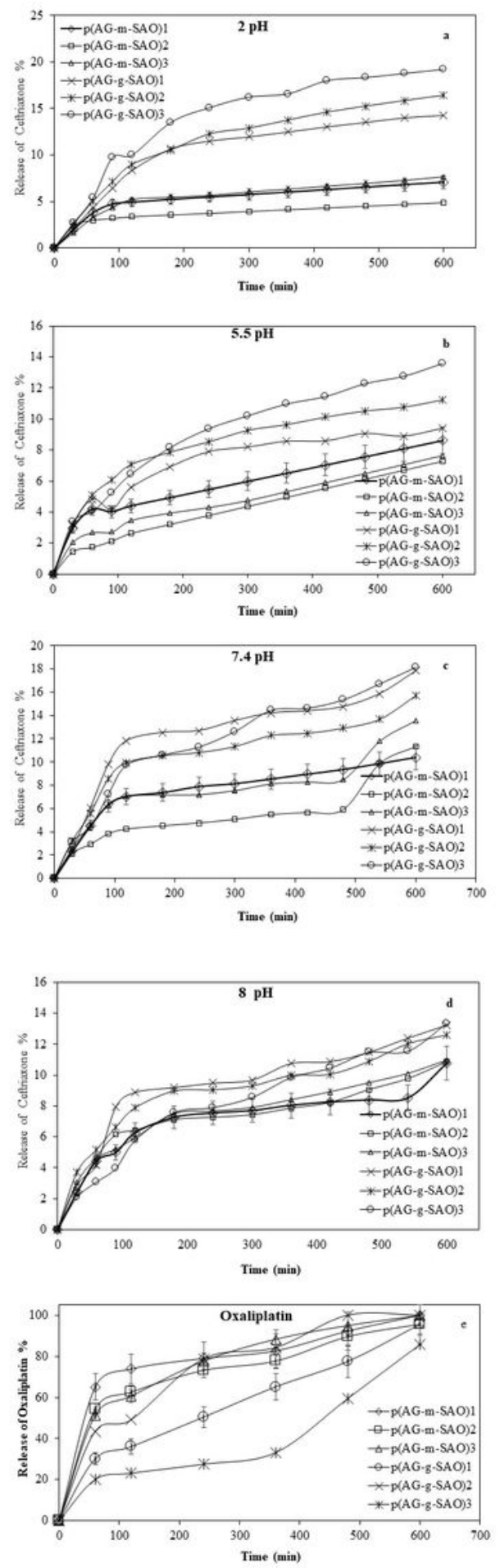

Figure 5

Release behavior of Ceftriaxone (a) $2.0 \mathrm{pHs}$ (b) $5.5 \mathrm{pHs}$ (c) $7.4 \mathrm{pHs}$ (d) $8.0 \mathrm{pHs}$ from organohydrogels and (e) Oxaliplatin 7.4 pHs organohydrogels. (The first 600 min of Ceftriaxone and Oxaliplatin release were given in the graph). 